\title{
Influence of inorganic salts on biomass production, biochemical composition, and bioethanol production of Populus alba
}

\author{
Seon Jeong $\operatorname{Sim}^{(1)}$, \\ Seong Hyeon Yong ${ }^{(2)}$, \\ DongJin Park ${ }^{(3)}$, \\ Eunji Choi ${ }^{(2)}$, \\ Yuwon Seol ${ }^{(2)}$, \\ Hyun Jin Song ${ }^{(3)}$, \\ Mi Jin Jeong ${ }^{(4)}$, \\ Hak Gon Kim ${ }^{(1)}$, \\ Myung Suk Choi ${ }^{(2-5)}$
}

\begin{abstract}
Inorganic salts are very important for the biosynthesis of major components such as cellulose and lignin. In order to investigate biomass production, major components of the biosynthesis of plant cell wall and the bioethanol production of Populus alba, we examined the effect of inorganic salts on in vitro culture systems without specific mineral salts. The medium without $\mathrm{H}_{2} \mathrm{PO}_{4}^{-}$was supportive for Populus alba shoot growth, while the absence of $\mathrm{NH}_{4}^{+}$resulted in poor shoot growth. The medium without $\mathrm{H}_{2} \mathrm{PO}_{4}{ }^{-}$and $\mathrm{Fe}^{3+}$ inhibited aboveground biomass production, whereas $\mathrm{NH}_{4}{ }^{+}$and $\mathrm{K}^{+}$deprivation led to an enhancement of the same. The root/shoot ratio of Populus alba in the medium without $\mathrm{H}_{2} \mathrm{PO}_{4}^{-}$was high compared with plants cultured in the control medium. $\mathrm{H}_{2} \mathrm{PO}_{4}^{-}$is deeply involved in lignin biosynthesis, and its removal has been shown to reduce the biosynthesis of lignin. Plants grown on nitrate-free medium were found to be good for enzymatic saccharification and ethanol production. The plants grown in the medium without $\mathrm{NO}_{3}{ }^{-}$showed $72.0 \%$ enzyme digestibility, and the yield of ethanol showed $9.58 \%$ ethanol productivity after 12 hours. These results can be used as the basis for producing high-quality biomass for future bioethanol production.
\end{abstract}

Keywords: Enzymatic Hydrolysis, Fermentation, Inorganic Salts, In vitro Culture, Populus alba

The short rotation coppice (SRC) is known as an effective way to enhance biomass massive production and reduce atmospheric $\mathrm{CO}_{2}$ accumulation (Amichev et al. 2012). SRC energy crops such as poplar (Populus spp.) are grown commercially for heat and power generation as a consequence of their rapid growth rate and favorable energy ratio (Rowe et al. 2009). Populus species play significant roles in global ecosystems and provide raw materials for the forest industry and fuels for rural areas in developing countries (IPCC 2008). Populus alba (P. alba) is the fastest growing among the Populus species and is easily propagated, and thus it serves as a biochemical and physiological conditions (Shibli et al. 2000). vitro monitoring". Nutrient media for ures are designed to $\mathrm{m}$ the plant tissue in a fully artificial environment. In vitro culturing allows the monitorquire nutrients in the soil to be carefully model for tree biotechnology (Bradshaw et al. 2000).

Crops grown for their high production reconsidered. SRC cultivation should also take into account soil nutrients and fertilization (Dimitriou \& Rutz 2015). Several studies of SRC, such as poplar and willow, have studied these nutrients, but they focused on the optimal cultivation environment. There have been no studies on the effect of inorganic salt components on plant cell wall composition.

Nutrient stress can cause a change in the content of lignin and other secondary metabolites in trees (Chapin 1991). Tree growth is generally associated with the ability to obtain mineral nutrients from the soil in a balanced amount. The factors that can alter mineral nutrition in plants may also affect the lignification process. Yet, the role of the mineral nutrients in lignification is still unclear. The regulation of nutrient supply in plants may be one of the most easily practicable ways of directing the biosynthesis of lignin and other compounds in plants.

Lignocellulosic biomass can be converted to bioethanol after pretreatment procedures, hydrolysis and subsequent fermentation. The lignocellulosic biomass is mainly composed of cellulose, hemicelluloses and lignin, along with smaller amounts of pectin, protein and ash (Jørgensen et al. 2007). Pretreatment has been viewed as one of the most important and expensive steps in releasing sugars from hemicellu- 
Tab. 1 - Mineral salt compositions of media for in vitro culture of $P$. alba used in this study. T1 (Control, HSM); T2 ( $\mathrm{HSM}$ without $\mathrm{NH}_{4}^{+}$); $\mathrm{T} 3$ ( $\mathrm{HSM}$ without $\left.\mathrm{NO}_{3}{ }^{-}\right)$; $\mathrm{T} 4$ ( $\mathrm{HSM}$ without $\left.\mathrm{H}_{2} \mathrm{PO}_{4}\right)^{-}$); 5 ( $\left(\mathrm{HSM}\right.$ without $\left.\mathrm{K}^{+}\right)$; $\mathrm{T} 6\left(\mathrm{HSM}\right.$ without $\left.\mathrm{Ca}^{2+}\right)$; $\mathrm{T} 7\left(\mathrm{HSM}\right.$ without $\mathrm{Mg}^{2+}$ ); T8 ( $\mathrm{HSM}$ without $\mathrm{Fe}^{3+}$ ).

\begin{tabular}{cccccccc}
\hline \multirow{2}{*}{ Medium } & \multicolumn{7}{c}{ Mineral salt $(\mathrm{mM})$} \\
\cline { 2 - 7 } & $\mathrm{NH}_{4}{ }^{+}$ & $\mathrm{NO}_{3}{ }^{-}$ & $\mathrm{H}_{2} \mathrm{PO}_{4}{ }^{-}$ & $\mathrm{K}^{+}$ & $\mathrm{Ca}^{2+}$ & $\mathrm{Mg}^{2+}$ & $\mathrm{Fe}^{3+}$ \\
\hline $\mathrm{T} 1$ & 0.515 & 0.985 & 0.031 & 0.503 & 0.748 & 0.751 & 0.010 \\
\hline $\mathrm{T} 2$ & 0 & 0.985 & 0.031 & 0.503 & 0.748 & 0.751 & 0.010 \\
\hline $\mathrm{T} 3$ & 0.515 & 0 & 0.031 & 0.503 & 0.748 & 0.751 & 0.010 \\
\hline T4 & 0.515 & 0.985 & 0 & 0.503 & 0.748 & 0.751 & 0.010 \\
\hline T5 & 0.515 & 0.985 & 0.031 & 0 & 0.748 & 0.751 & 0.010 \\
\hline T6 & 0.515 & 0.985 & 0.031 & 0.503 & 0 & 0.751 & 0.010 \\
\hline T7 & 0.515 & 0.985 & 0.031 & 0.503 & 0.748 & 0 & 0.010 \\
\hline T8 & 0.515 & 0.985 & 0.031 & 0.503 & 0.748 & 0.751 & 0 \\
\hline
\end{tabular}

loses and cellulose (Kadam et al. 2008). Removing lignin and hemicelluloses, the reduction of cellulose crystallinity and the increase of porosity during the pretreatment processes can significantly improve the enzymatic hydrolysis of cellulose contained in the lignocellulosic material (Singh \& Chen 2008). Many studies concerning the pretreatment step have been performed, such as the use of liquid hot water, dilute sulfuric acid, alkaline pretreatment ammonia fiber explosion (AFEX) and ammonia recycle percolation (ARP - Hu \& Ragauskas 2016). However, these pretreatment methods are still inefficient, highly expensive and not environmental-friendly. Recently, ionic liquids (ILs) have been proven to be effective as solvents for lignocellulose pretreatment. This method results in the rapid saccharification of cellulose and hemi cellulose, but it is too expensive, which remains a major obstacle to its commercialization. Therefore, it is very important that the content of lignin in the plant is low and the content of cellulose is high.

Variations in the chemical composition and physical properties of wood depend on plant species and the growth conditions related to their location (Mandre 2002), light environment (Pearcy \& Sims 1994), temperature (Waring 1991) and the availability of nutrients for trees (Field \& Mooney 1986).

The chemical and physical properties of the feedstock can affect the choice and efficiency of the biomass conversion process (Tillman 2000). The purpose of this study was to evaluate the effects of inorganic salts on the growth of poplar and biosynthesis of major compounds in plants using an in vitro culture system and to investigate the bio-ethanol production efficiency of poplar grown from each inorganic salt.

\section{Materials and methods}

Plant materials and preparation of medium with revised inorganic salts

The plant material of $P$. alba was distributed from the National Institute of Forest
Science and planted at the Forestry Education Expansion Center of Gyeongsang $\mathrm{Na}$ tional University (South Korea). Two-yearold seedlings were sampled and used for in vitro cultures. In vitro plants were subcultured every 4 weeks in $1 / 2$ MS medium (Murashige \& Skoog 1962) and cultured for 1 year. Plants used in the experiment were cultured for 6 weeks at a height of $5 \mathrm{~cm}$ in the early stage of culture. We used a plant with height of $15 \mathrm{~cm}$ as the sample for chemical analysis.

The medium was prepared to investigate the effects of inorganic salts on biomass production, the major components of the biosynthesis of plants and cell walls and the bioethanol production of P. alba. An MS medium was used for the in vitro culture of white poplar (Lambardi et al. 2000). In addition, in a previous study, it was found that $1 / 2$ MS medium is suitable for culture, and the concentration used in this study was determined within this range.

The $1 / 2$ MS solid medium was prepared by removing large amounts and trace inorganic salts. $\mathrm{T} 1$ is a basic medium composition for MS, and T2 to T8 are treatments in which nitrogen sources (ammonium and nitrate), potassium, calcium, magnesium and iron are removed (Tab. 1). Each treatment contains all of the other ingredients except inorganic salts. The revised medium was adjusted to $\mathrm{pH} 5.8$ after the addition of $0.7 \%$ Agar without the addition of growth regulators. The $\mathrm{pH}$ of the eight experimental treatments used in this study was 4.35.2; therefore, it was neutralized with $1 \mathrm{~N}$ $\mathrm{HCl}$ to reach an optimum $\mathrm{pH}$ of 5.8.

National Renewable Energy Laboratory (NREL Golden, CO, USA) analytical methods for biomass (NREL 1996) were used. Carbohydrates, lignins (acid-insoluble, acid soluble), extractives and the ash content of raw materials were determined according to NREL procedures (Sluiter et al. 2008). The reagents $\left(\mathrm{H}_{2} \mathrm{SO}_{4}\right)$ used for the analysis of chemical composition, lignin biosynthesis, enzymatic saccharification, ethanol fermentation, etc., were obtained from Sigma-Aldrich (Sigma Aldrich Corp., St. Louis, MO, USA).
In vitro culture in medium revised with inorganic salts

The $P$. alba stems were surface sterilized, segmented into $2-3 \mathrm{~cm}$ pieces and placed on $1 / 2$ MS solid medium to allow growth. In vitro plantlets were further placed in culture vessels containing $50 \mathrm{~mL}$ of $1 / 2 \mathrm{MS}$ basal medium containing sucrose $(3 \% \mathrm{w} / \mathrm{v})$. All cultures were maintained under a $16 \mathrm{~h}$ light $/ 8 \mathrm{~h}$ dark photoperiod in a growth chamber fitted with a cool fluorescent light emitting $25 \mu \mathrm{mol} \mathrm{m} \mathrm{m}^{-2} \mathrm{~s}^{-1}$ of photosynthetically active radiation (PAR).

To determine variations in biomass by inorganic salt treatments, individual shoots were cultured on the revised $1 / 2$ MS solid medium without any plant growth regulators for 8 weeks. The effect of inorganic salts on the shoot growth and biosynthesis of major compounds on the plantlets was studied by culturing P. alba on $1 / 2$ MS medium free from one inorganic salt at a time (Tab. 1).

The shoot growth and growth appearance were recorded after 8 weeks of culture. The number of shoots and leaves, withering rate, and fresh and dry biomass weights were divided into above and below-ground, and the root/shoot rates were calculated according to the measured values.

The leaf chlorophyll content in nutrienttreated plants was measured using an SPAD (Soil Plants Analysis Development)$502^{\circledR}$ portable chlorophyll meter (Minolta Co., Ltd., Japan). The SPAD values were repeatedly taken at the center of the leaves throughout the experiments.

\section{Lignin biosynthesis assay}

For the histochemical analysis of lignin in biomass, the lignin of the cultured biomass was stained with Wiesner reagents (Geiger \& Fuggerera 1979). The poplar shoots were sectioned freehand with a sharp razor blade, and sections were stained with Wiesner reagents. The lignin component was identified as a red color when observed under a light microscope.

\section{Chemical composition of P. alba}

biomass obtained in different media

To determine the chemical composition of biomass, National Renewable Energy Laboratory analytical methods (NREL 1996) were applied. The shoot tissues (100 g dry weight) were chopped into small pieces and dried at $70{ }^{\circ} \mathrm{C}$ for $24 \mathrm{~h}$ in vacuo, extracted with ethanol in a Soxhlet extractor for $3 \mathrm{~h}$ and dried at $105^{\circ} \mathrm{C}$ for $48 \mathrm{~h}$ in vacuo. Lignin and holocellulose contents were determined after delignification with $\mathrm{NaClO}_{2}$ (Wise et al. 1946); briefly, a $2.5 \mathrm{~g}$ biomass of defatted P. alba was repeatedly (three times) treated with $1 \mathrm{~g}$ of $\mathrm{NaClO}_{2}$ in dilute acetic acid solution $(0.2 \mathrm{~mL})$ at $70^{\circ} \mathrm{C}$ for $1 \mathrm{~h}$. The delignified product, holocellulose, was filtered, washed with distilled water, dried at $105^{\circ} \mathrm{C}$ for $48 \mathrm{~h}$ in vacuo and weighed.

The $a$-cellulose content was determined as the insoluble residue in the $\mathrm{NaOH}(17.5 \%)$ 
aqueous solution. A flask containing a $1 \mathrm{~g}$ sample of the holocellulose obtained according to the process above was dissolved in $\mathrm{NaOH}$. The mixture was stirred for $30 \mathrm{~min}$ at $20{ }^{\circ} \mathrm{C}$, and $25 \mathrm{~mL}$ of distilled water was then added to the mixture. After $5 \mathrm{~min}$, the residue was filtrated, and then supplemented with $40 \mathrm{~mL}$ of $10 \%$ acetic acid and allowed to stand. The resulting residue was collected by filtration and washed with $1 \mathrm{~L}$ of boiling water. The residue that contained $a$-cellulose was finally dried at $105^{\circ} \mathrm{C}$ for $48 \mathrm{~h}$ in vacuo and weighed. The contents of lignin, holocellulose, and a-cellulose in the original $P$. alba chips were calculated as dry weights relative to the original plant mass. The a-cellulose content was quantified as cellulose. The hemicellulose content of the biomass was determined by the subtraction of the a-cellulose from that of holocellulose.

To observe cellulose using field emission scanning electron microscopy (Fe-SEM) analysis, delignificated tissues were airdried before being used for microscopic examination. The $a$-cellulose solids were transferred to carbon tape on copper stubs and sputtered with gold (10 $\mathrm{mA}$ and $300 \mathrm{~s}$ ) using a high-resolution sputter coater (Agar Scientific Ltd., Stansted, UK). Fe-SEM investigations were carried out with a Philips XL30 S-FEG ${ }^{\circledast}$ Microscope (Netherlands) operated at $15 \mathrm{kV}$, Magnification $200 \times$ or $300 \times$. Images were acquired with Quartz $\mathrm{PCl}^{\circledR}$ Version 4 software (Hitachi high-technologies, Japan).

\section{Enzymatic hydrolysis and alcohol \\ fermentation}

Enzymatic hydrolysis was carried out on the non-delignified raw material. For enzymatic hydrolysis, $1 \mathrm{~g}$ of extractive-free dry biomass was finely ground and transferred to a $250 \mathrm{~mL}$ Erlenmeyer flask containing 50 $\mathrm{mL}$ of $0.1 \mathrm{M}$ sodium citrate buffer $(\mathrm{pH} 4.8)$. Next, appropriate amounts of cellulase (58.56 $\mathrm{FPU} \mathrm{g}^{-1}$ ) and an equal amount of $\beta$ glucosidase (24.2 FBG g-1) were added. The flask was placed in a shaking incubator (IS97IR, Jeio-Tech (o. Korea) and maintained at $50{ }^{\circ} \mathrm{C}$ for $36 \mathrm{~h}$ (150 rpm). The released glucose in the medium was analyzed with a mutarotase-GOD method employing a glucose CIl-test kit (Wako Pure Chemical Industrie Ltd., Osaka, Japan) after the heatdenaturing of enzymes $\left(100{ }^{\circ} \mathrm{C}\right.$ for $\left.10 \mathrm{~min}\right)$. The enzymes used for enzymatic hydrolysis

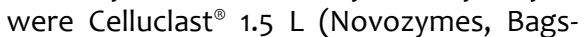
vaerd, Denmark), cellulase from Trichoderma reesei and Viscozyme L (Novozymes) as $\beta$-glucosidase.

Regarding fermentation, Saccharomyces cerevisiae KCCM 11215 was used for the alcohol fermentation study. The inoculum required for fermentation was developed in YM (Yeast and Mold) liquid medium (yeast extract $3 \mathrm{~g} \mathrm{~L}^{-1}$, malt extract $3 \mathrm{~g} \mathrm{~L}^{-1}$, peptone $5 \mathrm{~g} \mathrm{~L}^{-1}$ and dextrose $\left.10 \mathrm{~g} \mathrm{~L}^{-1}\right)$. Later, an inoculum $\left(1.5 \times 10^{8}\right.$ cells $\left.\mathrm{mL}^{-1}\right)$ was seeded to fermentation broth $(5 \% \mathrm{v} / \mathrm{v})$.

Ethanol production was quantified by a gas chromatograph (GC - Agilent Technologies, Santa Clara, CA, USA). The fermentation broth obtained after $36 \mathrm{~h}$ was filtered through a $0.2 \mu \mathrm{m}$ filter before GC analysis to remove any coarse particles (Krishna \& Chowdary 2000) for alcohol estimation. The GC was equipped with an HPFFAP column of $30 \mathrm{~m}$ with an ID $0.25 \mathrm{~mm}$. The detector and injection port were maintained at $200{ }^{\circ} \mathrm{C}$. The combustion gas was a mixture of hydrogen and air, and nitrogen was used as a carrier gas at a flow rate of $40 \mathrm{~mL} \mathrm{~min}^{-1}$. The quantification of ethanol by the GC was obtained by comparison with a standard curve generated based on the detector response to known amounts of alcohol.

\section{Statistical analysis}

A one-way ANOVA was used to test for differences in $P$. alba growth. Means were separated by Duncan's multiple range test $(a=0.05)$. Values were expressed as means \pm standard error (SE). All data sets were subjected to analysis with the SPSS ${ }^{\circledR}$ package (SPSS, Inc. Chicago, IL, USA).

\section{Results and discussion}

The appearance of shoot growth in medium revised with inorganic salts

The growth of $P$. alba was influenced by the presence of different inorganic salts in the medium to varying extents (Tab. 2). Major variations were observed with respect to leaf color, leaf width, shoot number and plant height. The leaf color changed to yellow in the absence of $\mathrm{K}^{+}$in the medium. Poplar stems were fairly well proliferating when cultured in media free from $\mathrm{Ca}^{2+}$. The leaves of poplar were observed to be wider in $\mathrm{NH}_{4}^{+}$and $\mathrm{Mg}^{2+}$ deficient mediums; however, the removal of $\mathrm{NO}_{3}{ }^{-}$and $\mathrm{H}_{2} \mathrm{PO}_{4}{ }^{-}$from growth medium produced narrow plant leaves with the passage of time.

The pattern of shoot growth in the presence or absence of various inorganic salts

Tab. 2 - Influence of various mineral salts treatment on the shoot growth of P. Alba. Values are mean shoot growth (in $\mathrm{cm}$ ) of five replicates \pm standard error. Different letters indicate significant differences $(\mathrm{p}<0.05)$ among populations after Duncan's multiple range tests. (T1): Control, $\mathrm{HSM}$; (T2): $\mathrm{HSM}$ without $\mathrm{NH}_{4}{ }^{+} ;(\mathrm{T} 3)$ : $\mathrm{HSM}$ without $\mathrm{NO}_{3}$; (T4): HSM without $\mathrm{H}_{2} \mathrm{PO}_{4} ;(\mathrm{T} 5)$ : $\mathrm{HSM}$ without $\mathrm{K}^{+} ;(\mathrm{T} 6)$ : $\mathrm{HSM}$ without $\mathrm{Ca}^{2+}$; (T7): HSM without $\mathrm{Mg}^{2+}$; (T8): $\mathrm{HSM}$ without $\mathrm{Fe}^{3+} ;\left({ }^{* * *}\right)$ : $P<0.001$; (NS): not significant $(P>0.05)$.

\begin{tabular}{cccccc}
\hline \multirow{2}{*}{ Medium } & \multicolumn{5}{c}{ Culture period (days) } \\
\cline { 2 - 6 } & 1 & 14 & 28 & 42 & 56 \\
\hline T1 & $2.15 \pm 0.23^{\mathrm{a}}$ & $2.53 \pm 0.33^{\mathrm{c}}$ & $6.18 \pm 0.26^{\mathrm{bc}}$ & $8.57 \pm 0.44^{\mathrm{ab}}$ & $9.92 \pm 0.47^{\mathrm{a}}$ \\
\hline T2 & $2.64 \pm 0.13^{\mathrm{a}}$ & $4.59 \pm 0.36^{\mathrm{a}}$ & $8.77 \pm 0.74^{\mathrm{a}}$ & $10.11 \pm 0.78^{\mathrm{a}}$ & $11.36 \pm 0.23^{\mathrm{a}}$ \\
\hline T3 & $2.43 \pm 0.28^{\mathrm{a}}$ & $2.87 \pm 0.16^{\mathrm{c}}$ & $3.69 \pm 0.22^{\mathrm{d}}$ & $3.89 \pm 0.23^{\mathrm{c}}$ & $4.19 \pm 0.26^{\mathrm{c}}$ \\
\hline T4 & $2.71 \pm 0.05^{\mathrm{a}}$ & $3.26 \pm 0.18^{\mathrm{bc}}$ & $4.12 \pm 0.22^{\mathrm{d}}$ & $4.44 \pm 0.24^{\mathrm{c}}$ & $4.62 \pm 0.29^{\mathrm{c}}$ \\
\hline T5 & $2.47 \pm 0.19^{\mathrm{a}}$ & $4.18 \pm 0.43^{\mathrm{ab}}$ & $8.16 \pm 0.62^{\mathrm{ab}}$ & $10.11 \pm 0.56^{\mathrm{a}}$ & $10.46 \pm 0.63^{\mathrm{a}}$ \\
\hline T6 & $2.45 \pm 0.19^{\mathrm{a}}$ & $2.76 \pm 0.24^{\mathrm{c}}$ & $5.14 \pm 0.60^{\mathrm{cd}}$ & $7.01 \pm 0.37^{\mathrm{b}}$ & $7.59 \pm 0.41^{\mathrm{b}}$ \\
\hline T7 & $2.43 \pm 0.11^{\mathrm{a}}$ & $3.95 \pm 0.28^{\mathrm{ab}}$ & $6.32 \pm 0.86^{\mathrm{bc}}$ & $8.86 \pm 1.45^{\mathrm{ab}}$ & $9.55 \pm 1.38^{\mathrm{ab}}$ \\
\hline T8 & $2.59 \pm 0.14^{\mathrm{a}}$ & $4.61 \pm 0.45^{\mathrm{a}}$ & $7.83 \pm 1.00^{\mathrm{ab}}$ & $9.67 \pm 1.11^{\mathrm{a}}$ & $10.41 \pm 1.04^{\mathrm{a}}$ \\
\hline$P$-value & NS & $* * *$ & $* * *$ & $* * *$ & $* * *$ \\
\hline
\end{tabular}

is shown in Tab. 2. The shoot growth pattern was dependent on inorganic salts and their concentrations. The shoot growth rate of $P$. alba was high when the plant was cultured in medium without $\mathrm{NH}_{4}^{+}$(mean height $=11.36 \mathrm{~cm}$ ), while the plantlets cultured in the medium free from $\mathrm{NO}_{3}$ showed poor shoot growth. These results indicate that the ammonium ion has an adverse effect on plant growth. The use of nitrogen sources is different for each plant tion of $\mathrm{NH}_{4}{ }^{+}$to some plant species causes toxicity and reduced growth. Yan \& Xu cantly stimulated the growth of aboveground growth $\left(8.4 \% \mathrm{~g}^{-1} \mathrm{~N}\right)$, whereas $\mathrm{NH}_{4}^{+}$ addition showed a greater effect on belowground growth $\left(5.9 \% \mathrm{~g}^{-1} \mathrm{~N}\right)$.

The plantlets cultured on the medium without $\mathrm{H}_{2} \mathrm{PO}_{4}$ - showed poor shoot growth. Phosphorus also influenced the growth of $P$. alba. As phosphorus is an essential macronutrient for plant growth, it limits crop production in many regions of the world (Holford 1997). Gangawar \& Parameshwaran (1976) observed an enhancement in the total photosynthetic area with increasing levels of phosphorus, which ultimately produced higher amounts of dry matter.

The number of stems per individual was different for each medium (Tab. 3). In the medium with a calcium ion removed, the number of stems was very large. The number of leaves was also different for each medium. In the medium where calcium ion was removed, the number of leaves was also overwhelmingly high. There was no significant difference in the number of withered plants. The content of chlorophyll was significantly different among treatments. The treatments with the lowest chlorophyll content were nitrate-free media, and there were no significant differences from the control treatments of all inorganic salts in the media with calcium, magnesium and iron removed.

In the calcium-deficient medium, stem species. It has been reported that the addi(2018) reported that $\mathrm{NO}_{3}$ addition signifi- 
Tab. 3 - Influence of various mineral salts treatment on the shoot growth of P. Alba. Values are mean shoot growth (in $\mathrm{cm}$ ) of five replicates \pm standard error. Different letters indicate significant differences $(\mathrm{p}<0.05)$ among populations after Duncan's multiple range tests. (T1): Control, $\mathrm{HSM}$; (T2): $\mathrm{HSM}$ without $\mathrm{NH}_{4}{ }^{+}$; (T3): $\mathrm{HSM}$ without $\mathrm{NO}_{3}^{-}$; (T4): $\mathrm{HSM}$ without $\mathrm{H}_{2} \mathrm{PO}_{4}$; (T5): $\mathrm{HSM}$ without $\mathrm{K}^{+}$; (T6): $\mathrm{HSM}$ without $\mathrm{Ca}^{2+}$; (T7): HSM without $\mathrm{Mg}^{2+}$; (T8): $\mathrm{HSM}$ without $\mathrm{Fe}^{3+} ;(* * *): P<0.001$; (NS): not significant $(P>0.05)$.

\begin{tabular}{ccccc|}
\hline Treatment & $\begin{array}{c}\text { No. of } \\
\text { shoots/explant }\end{array}$ & No. of leaves & Withering rate & Chlorophyll \\
\hline T1 & $1.00 \pm 0.00^{\mathrm{b}}$ & $11.25 \pm 0.25^{\mathrm{b}}$ & $0.00 \pm 0.00^{\mathrm{a}}$ & $33.58 \pm 1.75^{\mathrm{a}}$ \\
\hline T2 & $1.00 \pm 0.00^{\mathrm{b}}$ & $10.40 \pm 0.45^{\mathrm{bc}}$ & $0.00 \pm 0.00^{\mathrm{a}}$ & $13.80 \pm 3.75^{\mathrm{b}}$ \\
\hline T3 & $1.00 \pm 0.00^{\mathrm{b}}$ & $7.00 \pm 0.50^{\mathrm{c}}$ & $0.06 \pm 0.27^{\mathrm{a}}$ & $8.50 \pm 4.51^{\mathrm{b}}$ \\
\hline T4 & $1.00 \pm 0.00^{\mathrm{b}}$ & $7.00 \pm 0.50^{\mathrm{c}}$ & $0.03 \pm 0.22^{\mathrm{a}}$ & $10.23 \pm 5.14^{\mathrm{b}}$ \\
\hline T5 & $1.00 \pm 0.00^{\mathrm{b}}$ & $11.80 \pm 0.65^{\mathrm{b}}$ & $0.03 \pm 0.22^{\mathrm{a}}$ & $15.55 \pm 2.48^{\mathrm{b}}$ \\
\hline T6 & $8.20 \pm 1.19^{\mathrm{a}}$ & $35.00 \pm 3.45^{\mathrm{a}}$ & $0.00 \pm 0.00^{\mathrm{a}}$ & $37.03 \pm 1.20^{\mathrm{a}}$ \\
\hline T7 & $1.40 \pm 0.45^{\mathrm{b}}$ & $12.80 \pm 0.82^{\mathrm{b}}$ & $0.06 \pm 0.55^{\mathrm{a}}$ & $29.55 \pm 3.12^{\mathrm{a}}$ \\
\hline T8 & $1.00 \pm 0.00^{\mathrm{b}}$ & $11.40 \pm 0.27^{\mathrm{b}}$ & $0.05 \pm 0.67^{\mathrm{a}}$ & $30.15 \pm 1.15^{\mathrm{a}}$ \\
\hline$P$-value & $* * *$ & ${ }^{* * *}$ & $\mathrm{NS}$ & $* * *$ \\
\hline
\end{tabular}

growth was reduced, and the stem and leaf numbers increased. This result implies that calcium has a great influence on the growth of P. alba. Parvin et al. (2015) reported that calcium significantly increased plant height in the growth of each step of tomato. The best results here were found at a concentration of $5 \mathrm{mM}$ of calcium. Calcium is a signaling molecule and acts as a second messenger which is increased in the cytosol by activating the influx channe both in the plasma membrane and tono plast and plays a significant role in mediating mechanisms involved in the recognition and response to abiotic stresses in plants (Kader \& Lindberg 2010).

The variation in biomass production was analyzed by observations with in vitro cultivated shoots after 8 weeks of culture (Tab. 4). The inorganic salt composition of the medium influenced both the above and below-ground biomass production of in vitro cultured P. alba. Biomass production in media with the omission of inorganic salts was enhanced compared to the control. $\mathrm{H}_{2} \mathrm{PO}_{4}$ and $\mathrm{Fe}^{3+}$ deprivation inhibited the quantity of above-ground biomass, but $\mathrm{NH}_{4}^{+}$and $\mathrm{K}^{+}$ limitation enhanced the production of above-ground biomass. On the other hand, the medium without $\mathrm{K}^{+}$dramatically supported below-ground biomass production. However, other treatments did not influence the production of below-ground biomass. These results indicated that phosphate is an important factor which is responsible for shoot biomass production. Fredeen et al. (1989) reported that low phosphate has the most striking effect on biomass production, with $85 \%$ reduction in total leaf area and $78 \%$ reduction in shoot dry weight at low phosphate levels in the medium. Furthermore, $\mathrm{Fe}^{3+}$ is known to affect plant root growth and to improve drought resistance in plants (Snyder \& Schmidt 1974).

The root/shoot $(R / S)$ ratio of $P$. alba was variable (0.09-0.29) depending upon the media components. $\mathrm{R} / \mathrm{S}$ ratio was high (0.29) compared with the control (0.09) following the removal of $\mathrm{H}_{2} \mathrm{PO}_{4}^{-}$from media. Also, the $\mathrm{R} / \mathrm{S}$ ratio was high (1.00) in the medium free from $\mathrm{Ca}^{2+}$.

Tab. 4 - Influence of mineral salts on $P$. alba biomass production. (R/S ratio): root dry weight (g) / shoot dry weight (g); ( 11 1): Control, $\mathrm{HSM}$; (T2): HSM without $\mathrm{NH}_{4}^{+} ;\left(\mathrm{T}_{3}\right)$ : HSM without $\mathrm{NO}_{3} ;$ (T4): $\mathrm{HSM}$ without $\mathrm{H}_{2} \mathrm{PO}_{4} ;$; (T5): HSM without $\mathrm{K}^{+} ;(\mathrm{T} 6)$ : $\mathrm{HSM}$ without $\mathrm{Ca}^{2+} ;(\mathrm{T} 7)$ : HSM without $\mathrm{Mg}^{2+}$; (T8): $\mathrm{HSM}$ without $\mathrm{Fe}^{3+} ;(* * *): P<0.001 ;(* *): P<0.01$; (NS): not significant $(P>0.05)$.

\begin{tabular}{cccccc}
\hline \multirow{2}{*}{ Medium } & \multicolumn{2}{c}{ Fresh Biomass $\left(\mathrm{g} \mathrm{plant}^{-1}\right)$} & \multicolumn{2}{c}{ Dry Biomass $\left(\right.$ g plant $\left.^{-1}\right)$} & \multirow{2}{R}{ R/S } \\
\cline { 2 - 5 } & Aboveground & Underground & Aboveground & Underground & ratio \\
\hline T1 & $0.62 \pm 0.01^{\mathrm{e}}$ & $0.09 \pm 0.00^{\mathrm{c}}$ & $0.09 \pm 0.00^{\mathrm{d}}$ & $0.01 \pm 0.00^{\mathrm{b}}$ & 0.09 \\
\hline T2 & $1.63 \pm 0.06^{\mathrm{a}}$ & $0.17 \pm 0.00^{\mathrm{b}}$ & $0.19 \pm 0.03^{\mathrm{a}}$ & $0.02 \pm 0.00^{\mathrm{b}}$ & 0.09 \\
\hline T3 & $0.72 \pm 0.01^{\mathrm{de}}$ & $0.16 \pm 0.00^{\mathrm{b}}$ & $0.12 \pm 0.04^{\mathrm{bcd}}$ & $0.03 \pm 0.00^{\mathrm{b}}$ & 0.22 \\
\hline T4 & $0.47 \pm 0.01^{\mathrm{f}}$ & $0.20 \pm 0.00^{\mathrm{b}}$ & $0.10 \pm 0.00^{\mathrm{d}}$ & $0.03 \pm 0.00^{\mathrm{b}}$ & 0.29 \\
\hline T5 & $1.41 \pm 0.06^{\mathrm{b}}$ & $0.19 \pm 0.00^{\mathrm{b}}$ & $0.17 \pm 0.02^{\mathrm{ab}}$ & $0.17 \pm 0.00^{\mathrm{a}}$ & 1.00 \\
\hline T6 & $1.42 \pm 0.06^{\mathrm{b}}$ & $0.35 \pm 0.00^{\mathrm{a}}$ & $0.16 \pm 0.01^{\mathrm{abc}}$ & $0.04 \pm 0.00^{\mathrm{b}}$ & 0.22 \\
\hline T7 & $0.88 \pm 0.02^{\mathrm{c}}$ & $0.13 \pm 0.00^{\mathrm{b}}$ & $0.13 \pm 0.00^{\mathrm{abcd}}$ & $0.02 \pm 0.00^{\mathrm{b}}$ & 0.12 \\
\hline T8 & $0.82 \pm 0.01^{\mathrm{cd}}$ & $0.02 \pm 0.00^{\mathrm{c}}$ & $0.11 \pm 0.01^{\mathrm{cd}}$ & $0.04 \pm 0.00^{\mathrm{b}}$ & 0.42 \\
\hline P-value & $* * *$ & $* * *$ & $* *$ & $* * *$ & - \\
\hline
\end{tabular}

The root/shoot ratio is usually given as the ratio of the weight of the roots versus the top of a plant. For most trees under normal conditions, the root/shoot ratio is 1:5 to 1:6 (Kramer 1969, Perry 1982), i.e., the top is 5 to 6 times heavier than the roots (Perry 1982). The difference in the root/ shoot ratio in this study is due to the relatively developed roots of the plant cultured in the medium with inorganic salts removed. An increase in soil fertility is commonly associated with a reduction in the root/shoot ratio; that is, shoot growth increases more in terms of weight than root growth (Coutts \& Philipson 1980). Several investigators have reported that phosphate is a key element that strongly influences the initiation and growth of cluster roots (Shane \& Lambers 2005).

The chemical composition of P. alba biomass obtained in different media

The chemical compositions of $P$. alba grown in other media with inorganic salts removed showed significant differences (Fig. 1). Total extract contents varied between $P$. alba cultivated in media with different inorganic salts. The content of extracts (i.e., secondary metabolites) includes nonstructural components of biomass such as waxes, fats, tannins, sugars, some resins and coloring matter (Jung et al. 2010). The extractive composition of $P$. alba was $37.21 \%$ in the medium free from $\mathrm{Ca}^{2+}$, which was a little higher than that of P. alba biomass produced using control media components. This result indicated that the biosynthesis of nonstructural components such as fat and resin is independent of $\mathrm{Ca}^{2+}$ in P. alba.

Calcium treatment is known to promote plant growth and biosynthesis, as a secondary metabolite of the plant (Ahmad et al. 2016). Calcium also plays a regulatory role in plant cell metabolism, signal transduction and in the absorption of nutrients across cell membranes (Talukdar 2012).

\section{Lignin biosynthesis in medium revised with inorganic salts}

The lignified tissues of $P$. alba were visualized with Wiesner (phloroglucinol- $\mathrm{HCl}$ ) reagents in 8-week-old plantlet stem middle cross-sections (Fig. 2). Although lignin was found in the whole section of $P$. alba pith, other plants grown under different nutrient conditions showed varying lignin contents from each other. Slightly later during the development of vascular tissue, cambium (ca) became covered with a continuous circumferential band of cells. The lignification appeared to extend throughout the primary medullary or interfascicular ray tissue (data not shown) and was initiated in the phloem fibers (pf) and xylem ( $x$ Fig. 2A-H).

Among various media, the nitrogen devoid (Fig. 2B, Fig. $2 \mathrm{C}$ ) and $\mathrm{H}_{2} \mathrm{PO}_{4}^{-}$removal (Fig. 2C) showed differences compared with other treatments. Lignin was noticed in the xylem tissue as well as in surround- 
ing cambial tissues. In particular, the plant tissue in most test conditions showed a deep red color due to the presence of lignin, but the control and $\mathrm{H}_{2} \mathrm{PO}_{4}$ free media had less lignin. This result highlights that lignin biosynthesis acts under the strict control of $\mathrm{H}_{2} \mathrm{PO}_{4}^{-}$contents. Mineral deficiency has been shown to affect lignin levels in crops (Frei 2013). Phosphorus deficiency has also been reported to increase lignin content (Eppendorfer \& Eggum 1994). There is little information on the effect of $P$ supply on lignin biosynthesis, but a lack or excess of inorganic elements such as P may induce the activation of enzymes involved in lignin biosynthesis (Frei 2013).

Pretreated poplar samples could be analyzed for lignin, a-cellulose, and hemicelluloses. The lignin content in P. alba was

Fig. 2 - Histochemical lignin staining in stem freehand cross-sections from 8 week old $P$. alba plantlets (white bar: $2 \mathrm{~mm}$ ). Lignin is stained red. (ca): cambium; (f): interfascicular fiber; (pf): phloem fibers; (pi): pith; (x): xylem. Magnification $\times 300$. (A) T1 (Control, HSM); (B) T2 (HSM without $\mathrm{NH}_{4}^{+}$); (C) T3 (HSM without $\mathrm{NO}_{3}{ }^{-}$); (D) T4 (HSM without $\mathrm{H}_{2} \mathrm{PO}_{4}^{-}$); (E) T5 (HSM without $\mathrm{K}^{+}$); (F) T6 (HSM without $\mathrm{Ca}^{2+}$ ); (G) T7 (HSM without $\left.\mathrm{Mg}^{2+}\right) ;(\mathrm{H})$ T8 ( $\mathrm{HSM}$ without $\mathrm{Fe}^{3+}$.

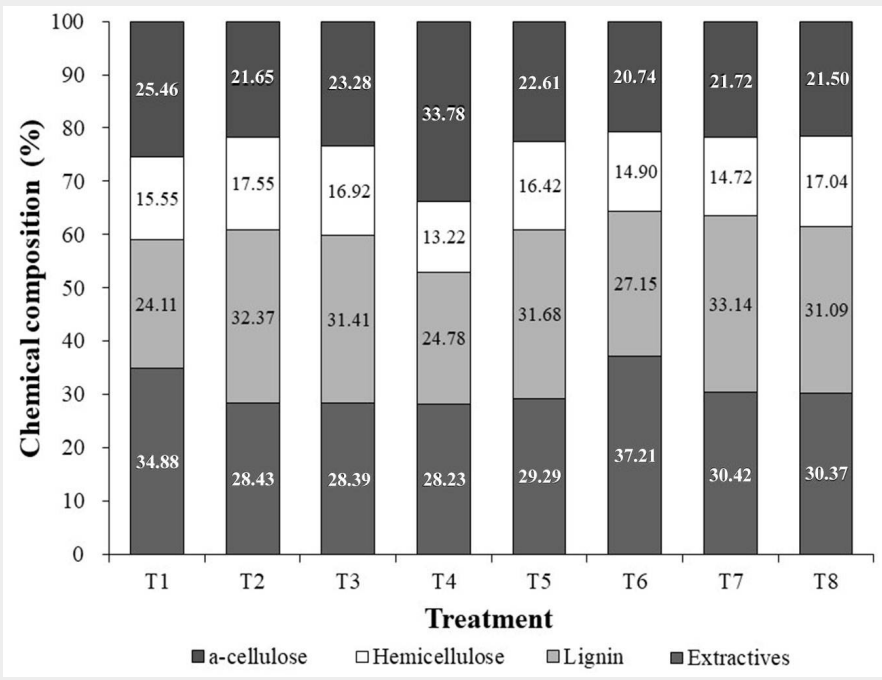

Fig. 1 - Chemical composition of P. alba biomass obtained from growth in different media. (T1): Control, HSM; (T2): HSM without $\mathrm{NH}_{4}^{+}$; (T3): HSM without $\mathrm{NO}_{3} ;(\mathrm{T} 4)$ : $\mathrm{HSM}$ without $\mathrm{H}_{2} \mathrm{PO}_{4}$; (T5): HSM without $\mathrm{K}^{+}$; (T6): HSM without $\mathrm{Ca}^{2+}$; (T7): HSM without $\mathrm{Mg}^{2+}$; (T8): HSM without $\mathrm{Fe}^{3+}$.
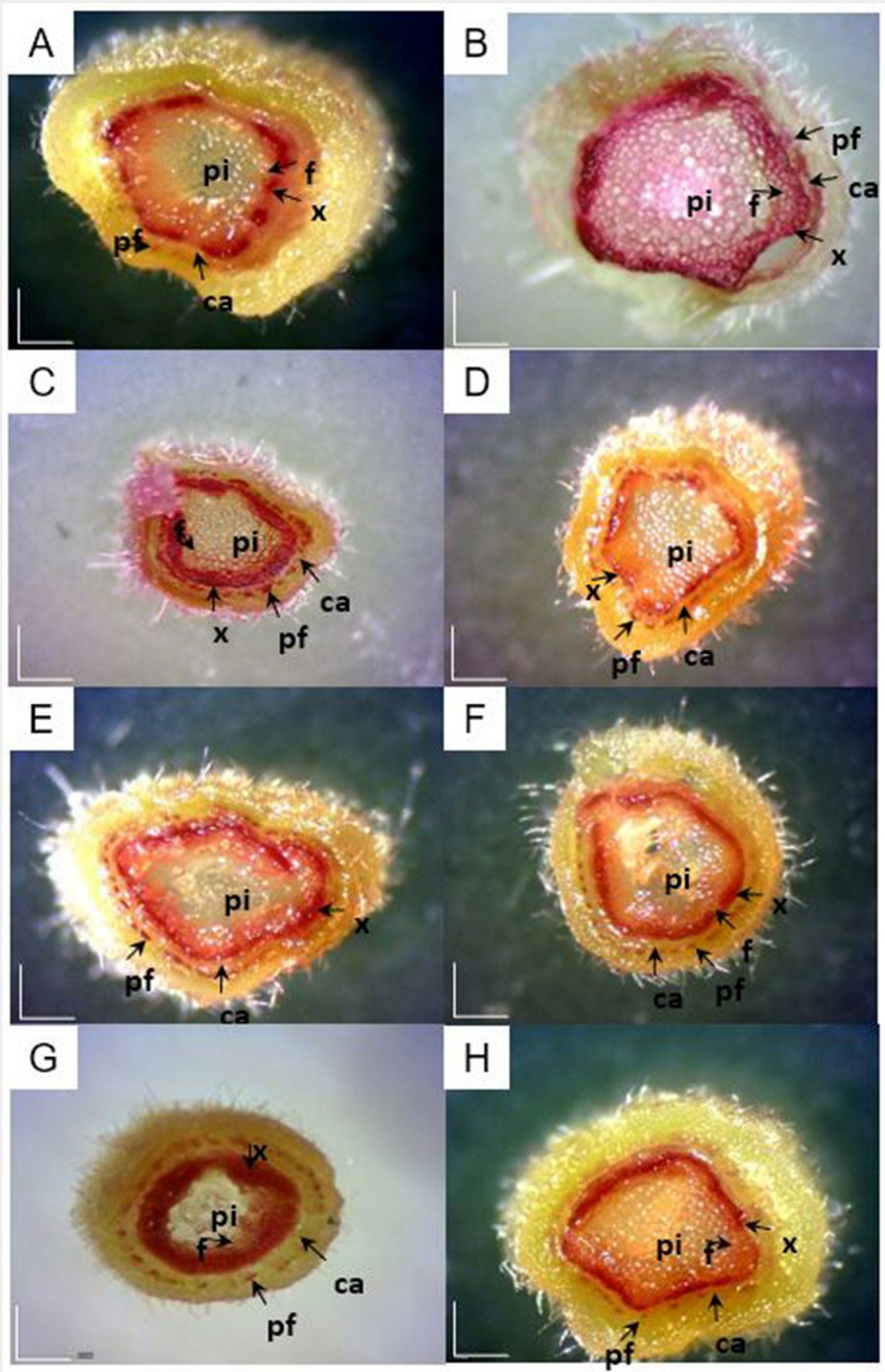


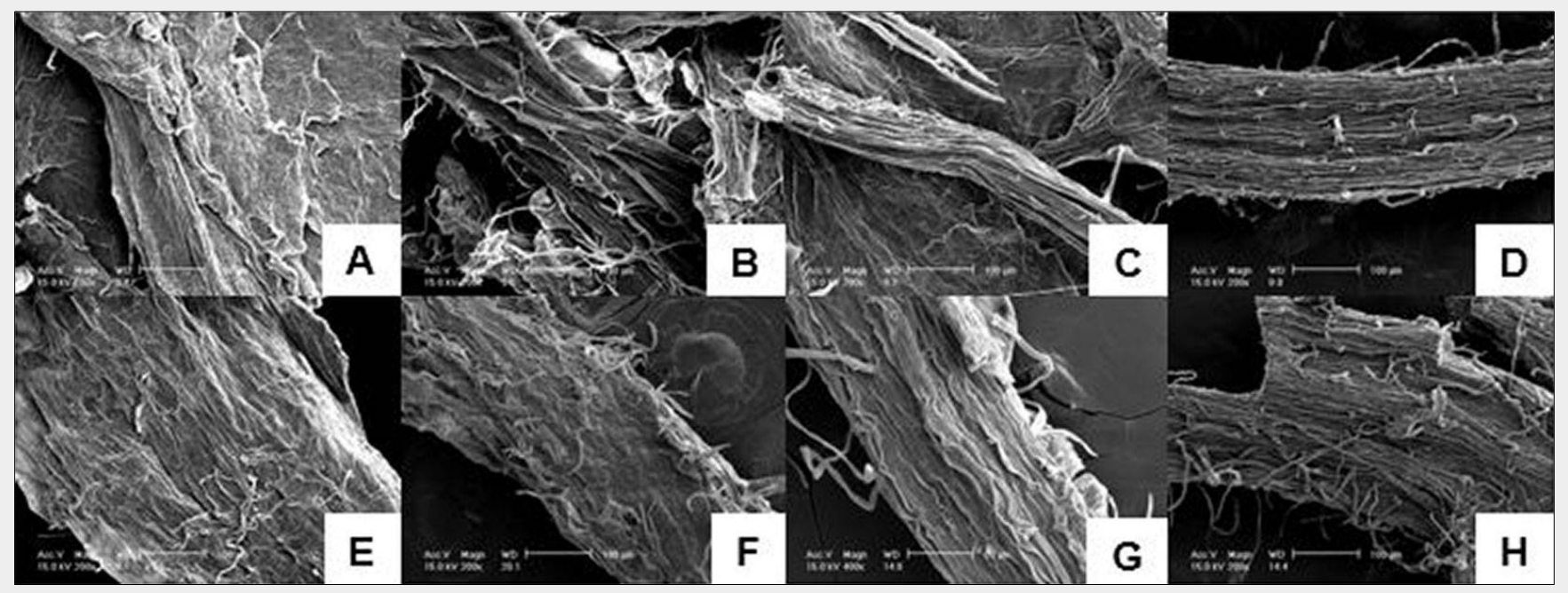

Fig. 3 - Fe-SEM images of a-cellulose from P. alba cultured under different nutrient conditions. (A) T1 (Control, HSM); (B) T2 (HSM without $\mathrm{NH}_{4}^{+}$); (C) T3 (HSM without $\mathrm{NO}_{3}^{-}$); (D) T4 (HSM without $\left.\mathrm{H}_{2} \mathrm{PO}_{4}^{-}\right)$; (E) T5 (HSM without $\left.\mathrm{K}^{+}\right)$; (F) T6 (HSM without Ca $\left.{ }^{2+}\right)$; (G) T7 ( $\mathrm{HSM}$ without $\mathrm{Mg}^{2+}$ ) and $(\mathrm{H}) \mathrm{T} 8\left(\mathrm{HSM}^{2}\right.$ without $\mathrm{Fe}^{3+}$ ).

$24.11 \%$ in the control and $24.78 \%$ in biomass obtained by culturing in the medium free from $\mathrm{H}_{2} \mathrm{PO}_{4}^{-}$(Fig. 1). Poplar hybrids have cellulose contents ranging from $42 \%$ to $49 \%$, hemicellulose from $16 \%$ to $23 \%$ and total lignin contents from $21 \%$ to $29 \%$ (Sannigrahi et al. 2010). In general, the lignin content of $P$. alba biomass of obtained in inorganic salt-free media was higher than that of the control, except for treatment without $\mathrm{H}_{2} \mathrm{PO}_{4}$. The growth of polar in the medium without $\mathrm{H}_{2} \mathrm{PO}_{4}^{-}$leads to a formation of lignin comparable to that in hybrid poplar and in other nutrient conditions. This result indicated that inorganic salts present in the medium influenced lignin biosynthesis. The high concentration of inorganic salts in the medium favors an increased cellulose level in biomass but a decreased lignin level. Entry et al. (1998) reported that a high $\mathrm{N}$ fertility rate decreased the concentration of lignin in longleaf pine (Pinus palustris Mill.) seedlings.

In the treatment without $\mathrm{NH}_{4}{ }^{+}\left(\mathrm{T}_{2}\right)$, the lignin content was $32.37 \%$, while the treatment without $\mathrm{Mg}^{2+}(\mathrm{T} 7)$ showed the highest lignin content (33.14\% - Fig. 1). Mg deficiency affects plant differentiation, which appears to influence lignin biosynthesis. Huang et al. (2019) also reported that Mg deficiency affected the differentiation of citrus roots. Phloem impairment in Mg-deficient leaves resulted in the cell wall lignification of both vascular cambium and spongy parenchyma cells. The hemicellulose content of $P$. alba was found to be 13.22$17.55 \%$ of dry weight (Fig. 1). Hemicellulose contents determined under various nutrient conditions were comparable to control plants; however, the hemicellulose content was low $(13.22 \%)$ in plant material obtained from media without $\mathrm{H}_{2} \mathrm{PO}_{4}$. Thus, inorganic salts slightly influenced the hemicellulose content of $P$. alba.

The composition of the a-cellulose present in P. alba stem is shown in Fig. 1. The $a-$ cellulose contents of $P$. alba ranged between $20.74 \%-33.78 \%$. Almost all cultivated plants contained a higher amount of a-cellulose than hemicellulose. However, the $a$ cellulose content in the tissue of popular cultured under $\mathrm{H}_{2} \mathrm{PO}_{4}-$ limitation was found to be higher than others. This observation indicated that $\mathrm{H}_{2} \mathrm{PO}_{4}^{-}$is a very important inorganic salt as it favors cellulose biosynthesis in P. alba. It has often been shown that growth is correlated with lignin and cellulose concentration in stems. The cellulose content increases with the radial growth of oak trees and decreases with its height (Bodirlau et al. 2007). Accordingly, intensive lignification may stop the extension of cell walls and cause the growth cessation of plants (Miidla 1989). There is a relationship between lignin and cellulose contents; lignin and cellulose biosynthesis in plants depends on several factors related both to the plant and to the environment. Among environmental factors, nutrient exposure has a close relationship with the cellulose level in plants. Tullus et al. (2010) reported that $\mathrm{N}, \mathrm{P}$ and $\mathrm{K}$ showed a strong relationship with lignin and cellulose levels in the stem wood of hybrid poplar clones.

The structure of a-cellulose purified from P. alba grown under control and different nutrient treatments was characterized by Fe-SEM. The morphology of the leaf sheath fibers and the cellulose microfibrils formed under differential nutrients is revealed in Fig. 3. Most of the lignin and hemicellulose was removed, and the cellulose microfibrils were separated from the original fibers on the completion of chemical treatments. The cellulose structure displayed a regular compact surface structure, and the fibers were arranged in bundles. The cellulose showed a characteristic morphology related to the nutrient growth environment. The cellulosic fiber in the nutrient conditions shown in Fig. 3A, Fig. 3E, Fig. $3 \mathrm{~F}$ and Fig. $3 \mathrm{C}$ showed a flat cellulose surface and did not show microfibril, whereas the cellulose surface shown in Fig. 3B exhibited both cellulose fibers and cellulose, condensed as microfibrils. Depending on the phosphate deficiency, it is necessary to look at the cellulose surface; phosphate deficiency smooths the cellulose surface. Cellulose surface morphology is related to enzyme glycosylation. In the enzymatic saccharification process for bioethanol production, the surface state and specific surface area of the substrate greatly influence the reaction rate of the enzyme with the substrate, which is one of the main factors influencing the saccharification efficiency (Youe et al. 2015). A smooth surface may prevent the enzyme solution from penetrating, thus the saccharification efficiency may be lowered (Kim et al. 2011).

\section{Enzymatic hydrolysis and alcohol fermentation of biomass}

The enzymatic digestibility of the non-delignified raw materials was investigated with Celluclast ${ }^{\circledR} 1.5 \mathrm{~L}$ and Viscozyme L. The time course of the enzymatic hydrolysis of $P$. alba is shown in Fig. 4. The saccharification of biomass occurred in direct relation to time. However, the reaction rate remained relatively low after $36 \mathrm{~h}$. The $P$. alba biomass obtained in the medium free from $\mathrm{NO}_{3}{ }^{-}$was saccharified to $72.0 \%$ after $36 \mathrm{~h}$ of hydrolysis, which was higher than for biomass produced from the treatment without $\mathrm{NH}_{4}^{+}(64 \%)$, without $\mathrm{H}_{2} \mathrm{PO}_{4}^{-}(60 \%)$ and without $\mathrm{Fe}^{3+}(60 \%)$. However, the enzymatic digestibility of poplar biomass produced from $\mathrm{Ca}^{2+}$ limited treatment was very low compared to other treatments.

The maximum cellulose yield $(33.78 \%)$ was obtained at $\mathrm{T}_{4}$ (free from $\mathrm{H}_{2} \mathrm{PO}_{4}^{-}$), whereas the medium without $\mathrm{NO}_{3}^{-}\left(\mathrm{T}_{3}\right)$ showed only a $23.28 \%$ cellulose yield. However, at $100 \mathrm{~g}$, the saccharification rate was $72 \%$ for $\mathrm{T} 3$ and $60 \%$ for $\mathrm{T} 4$, and when converted to sugar yield, T3 was $16.761 \mathrm{~g}$ and T4 was $20.268 \mathrm{~g}$. 


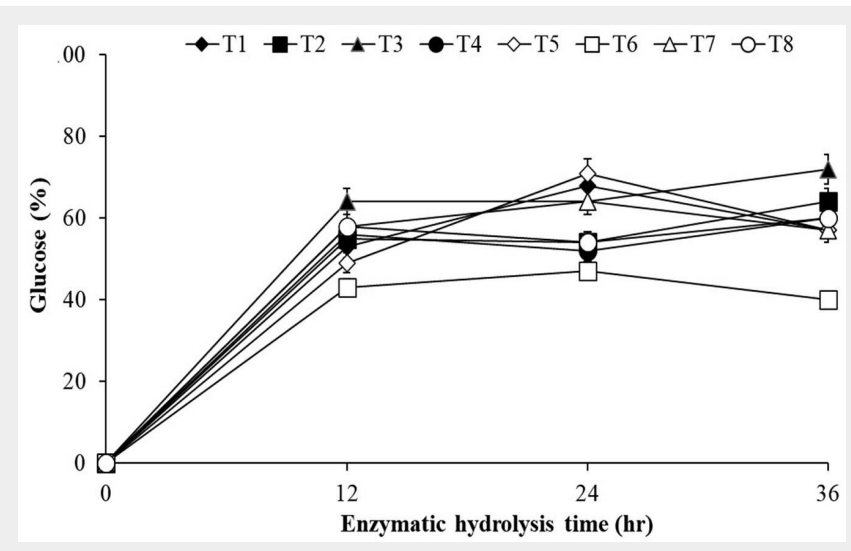

Fig. 4 - Time of enzymatic hydrolysis required for P. alba biomass obtained under different nutrient conditions. (T1): Control, $\mathrm{HSM}$; (T2): $\mathrm{HSM}$ without $\mathrm{NH}_{4}^{+}$; (T3): $\mathrm{HSM}$ without $\mathrm{NO}_{3}^{-}$; (T4): $\mathrm{HSM}$ without $\mathrm{H}_{2} \mathrm{PO}_{4}$; (T5): $\mathrm{HSM}$ without $\mathrm{K}^{+}$; (T6): HSM without $\mathrm{Ca}^{2+} ;(\mathrm{T} 7)$ : $\mathrm{HSM}$ without $\mathrm{Mg}^{2+}$; (T8): $\mathrm{HSM}$ without $\mathrm{Fe}^{3+}$.

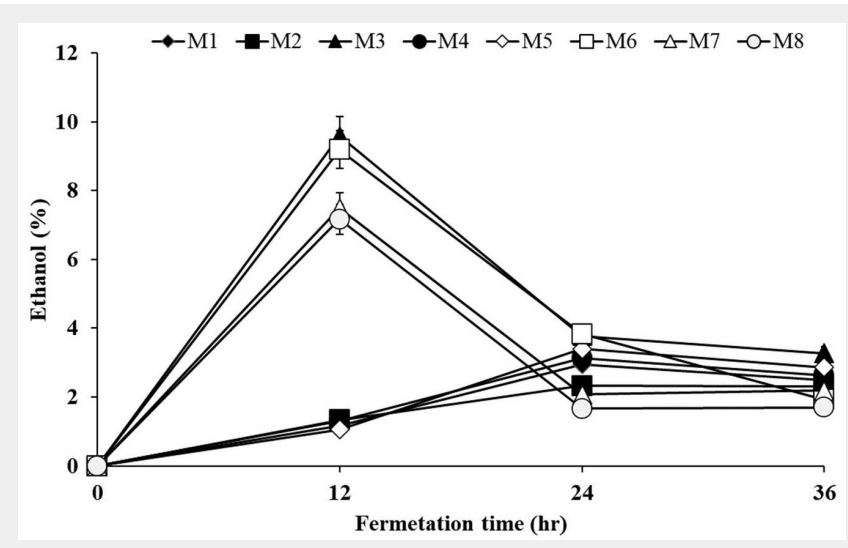

Fig. 5 - Rate of ethanol production from P. alba enzymatic hy-

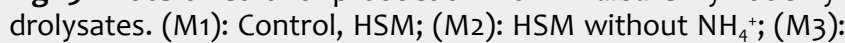
$\mathrm{HSM}$ without $\mathrm{NO}_{3} ;\left(\mathrm{M}_{4}\right)$ : $\mathrm{HSM}$ without $\mathrm{H}_{2} \mathrm{PO}_{4} ;(\mathrm{M} 5)$ : $\mathrm{HSM}$ without $\mathrm{K}^{+}$; (M6): $\mathrm{HSM}$ without $\mathrm{Ca}^{2+}$; (M7): $\mathrm{HSM}$ without $\mathrm{Mg}^{2+}$; (M8): $\mathrm{HSM}$ without $\mathrm{Fe}^{3+}$.
The treatment without $\mathrm{H}_{2} \mathrm{PO}_{4}^{-}$had a higher saccharification rate than the medium without $\mathrm{NO}_{3}^{-}$because the cellulose content was high, although the saccharification rate was low.

The enzymatic hydrolysis of the biomass obtained in the phosphate-deficient medium was not high compared to other treatments. The reason for this is shown in Fig. 3. It can be stated that this may be related to the surface shape of cellulose. In other words, it is determined to be the result of the difficulty of the penetration of the enzyme solution due to the smooth cellulose surface. In addition, the difference in the saccharification rate is thought to be due to the impurities contained in the cellulose saccharification solution, the difference in the cellulose structure (length difference) and the saccharification rate. In particular, in the case of $\mathrm{T}_{3}$ and $\mathrm{T}_{4}$, the saccharification rates $(72 \%$ and $60 \%$, respectively) for $100 \mathrm{~g}$ of raw materials (i.e., $28 \%$ and $40 \%$, respectively) are due to impurities. In particular, as can be seen from Fig. 1, the content of extractives is significantly higher in $\mathrm{T} 4$ than in other treatments. These results also suggest that inorganic salts can affect cellulose composition and therefore saccharification rates.

Lignocellulosic biomass cannot be saccharified by enzymes to high yields without a pretreatment, mainly because the lignin in plant cell walls forms a barrier against enzyme attack (Sewalt et al. 1997). However, in this study, the enzymatic digestibility of raw materials was relatively high without pretreatments. A high hydrolysis rate was shown without pretreatment. First, it was presumed that the lignin content was low due to the lack of inorganic salt; second, the sample used for analysis was an in vitro plant. That is, it is assumed that the selective mineral limit decreases the lignin content and crystallinity of cellulose and increases the surface area.

Biomass hydrolysate was subjected to the alcoholic fermentation process. The $S$. cerevisiae KCCM 1215-mediated ethanol production of popular enzymatic hydrolysates is shown in Fig. 5. Ethanol from fermented enzyme hydrolysate was detected at 23 minutes of retention time (Fig. 6). Ethanol production from $\mathrm{NO}_{3}^{-}$limited hydrolysates increased and reached a maximum level after $12 \mathrm{~h}$, yielding $9.58 \%$ of ethanol; however, after $24 \mathrm{~h}$, ethanol production decreased. The research have reported conversions (up to $2 \% \mathrm{w} / \mathrm{v}$ ethanol) in 4-6 days (Spangler \& Emert 1986). In this study, ethanol yielded up to $9.58 \%(\mathrm{w} / \mathrm{v})$ in $12 \mathrm{~h}$ from celluloses obtained from media without $\mathrm{NO}_{3}^{-}$and $9.18 \%(\mathrm{w} / \mathrm{v})$ in $12 \mathrm{~h}$ using

cellulases derived from biomass obtained from the medium without $\mathrm{Ca}^{2+}$, respectively. The reason for promoting bioethanol production by controlling the nitrogen source is that cell wall constituents are loose. Zhang et al. (2017) also reported that nitrogen fertilizer decreased cellulosic content and lignin content.

We have yet to establish the ethanol production conditions for P. alba. Enzymatic saccharification and ethanol fermentation conditions will lead to a very high rate of ethanol productivity of $9.58 \%$. These results indicated that the fermentation time for ethanol production could be shortened
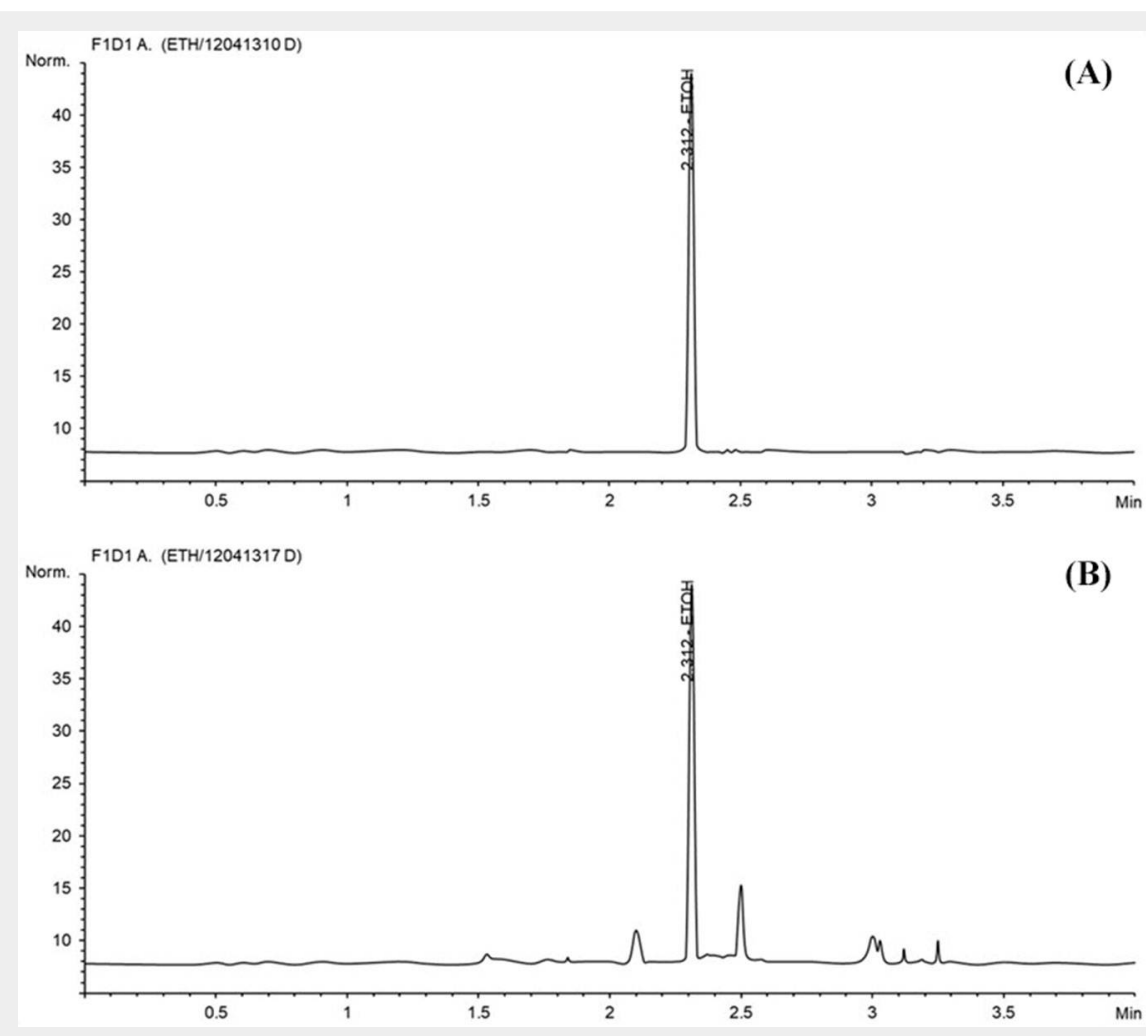

Fig. 6 - GC analysis of bioethanol produced by fermentation of enzyme saccharides. (A): ethanol standard; (B): ethanol produced from fermentation. 


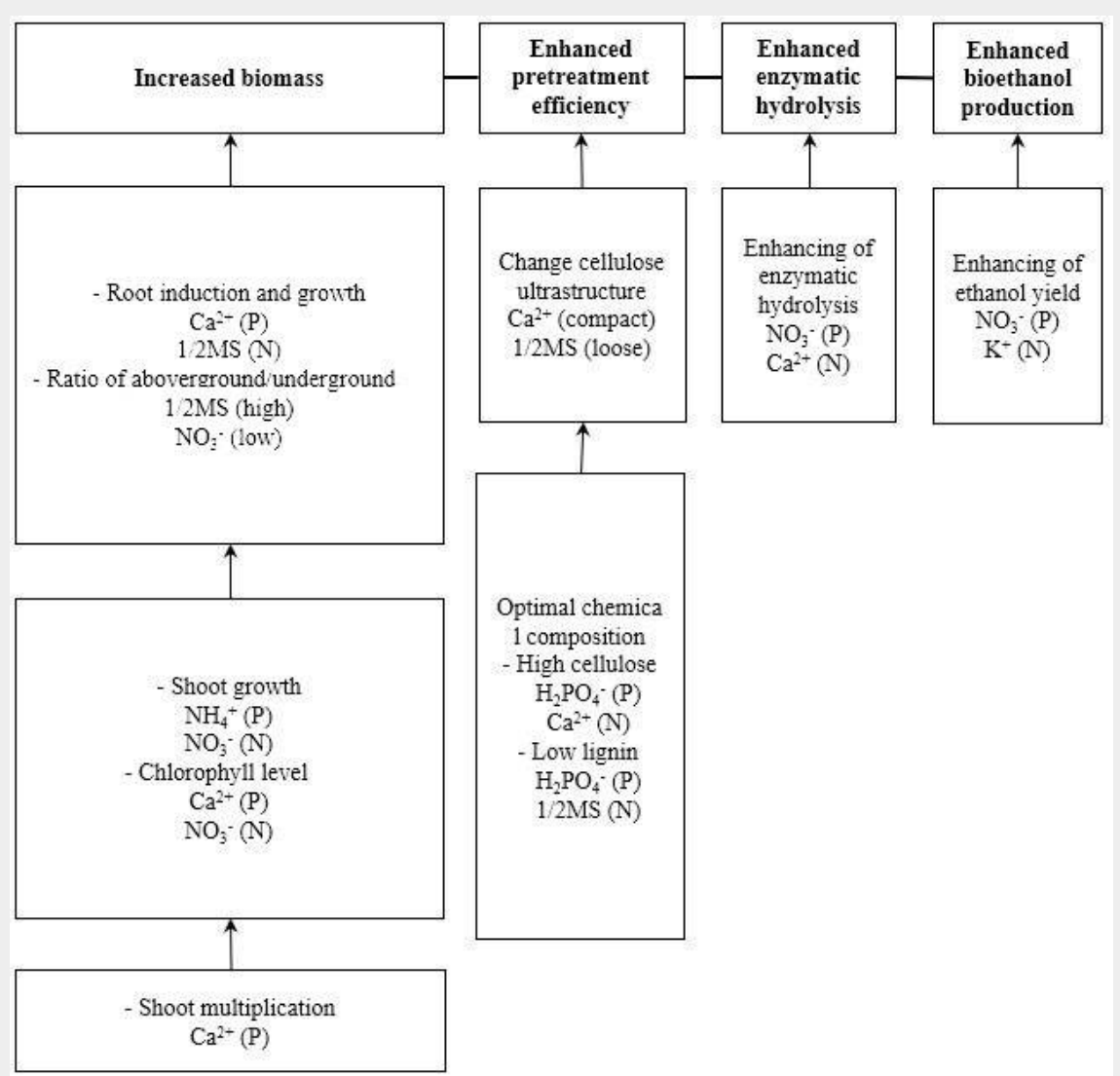

Fig. 7 - Effects of inorganic salts on biomass production, major components biosynthesis of plant and cell wall, and bioethanol production from in vitro cultured P. alba. (P): Positive; (N): Negative.

with plant cultivation under optimal nutrient conditions.

Inorganic salts showed both negative and positive effects on $\mathrm{P}$. alba growth (Fig. 7). Among inorganic salts, $\mathrm{H}_{2} \mathrm{PO}_{4}^{-}$is important for biomass, chemical biosynthesis and bioethanol production. Nutrient regulation may cause the unfastening of tough biomass components and help to accelerate the hydrolysis during pretreatment, which will ultimately reduce the cost of bioethanol production. An understanding of the optimal plant nutritional requirements would allow growers to adjust their fertilization program to soil types. These results can be used as basic data for proper fertilizer controls to yield quality biomass for bioethanol production in the future.

\section{Conclusion}

Our results showed that the regulation of inorganic salts is very important for biomass and bioethanol production. The appropriate use of inorganic salts can change the composition of plant cell walls. In particular, phosphoric acid and nitrogen sources have been shown to be involved in biomass production and cellulosic structure. For biomass production, $\mathrm{H}_{2} \mathrm{PO}_{4}$ showed high biomass productivity, but the enzyme saccharification rate was low, so bioethanol production from lignocellulosic biomass was found to be very important for selecting the appropriate inorganic salt.
The results of this study could be very useful for the short-term cultivation of feedstock for bioenergy production.

\section{Author Contribution}

SJS and SHY contributed equally to this paper (co-first authors).

\section{Acknowledgment}

This research was supported by the Basic Science Research Program through the National Research Foundation of Korea (NRF) funded by the Ministry of Education (2017R1D1A1B04036320) and the Forest Resources Management Project of the $\mathrm{Na}$ tional Forest Seed and Variety Center.

\section{References}

Ahmad P, Abdel Latef AA, Abd Allah EF, Hashem A, Sarwat M, Anjum NA, Gucel S (2016). Calcium and potassium supplementation enhanced growth, osmolyte secondary metabolite production, and enzymatic antioxidant machinery in cadmium-exposed chickpea (Cicer arietinum L.). Frontiers in Plant Science 7 (347): 1303. doi: $10.3389 /$ fpls.2016.00513

Amichev BY, Kurz WA, Smyth C, Van Rees KCJ (2012). The carbon implications of large-scale afforestation of agriculturally marginal land with short-rotation willow in Saskatchewan. Global Change Biology Bioenergy 4: 70-87. - doi: 10.1111/j.1757-1707.2011.01110.x

Bodirlau R, Spiridon I, Teaca CA (2007). Chemical investigation on wood tree species in a temper- ate forest in east-northern Romania. Bioresources 2: 41-57. - doi: 10.15376/biores.2.1.41-57 Bradshaw HD, Ceulemans R, Davis J, Stettler R (2000). Emerging model systems in plant biology: poplar (Populus) as a model forest tree. Journal of Plant Growth Regulation 19: 306-313. - doi: $10.1007 / \mathrm{s} 003440000030$

Chapin FS (1991). Effects of multiple environmental stresses on nutrient availability and use. In: "Response of Plants to Multiple Stresses" (Mooney HA, Winner WE, Pell EJ eds). Academic Press, Cambridge, UK, pp. 67-88.

Coutts MP, Philipson JJ (1980). Mineral nutrition and tree root growth. In: "Mineral Nutrition of Fruit Trees" (Atkinson D, Jackson JE, Sharples RO, Waller WM eds). Butterworths, London, UK and Boston, MS, USA, pp. 123-136. - doi: 10.1766o/ActaHortic.1980.92.16

Dimitriou I, Rutz D (2015). Sustainable short rotation coppice - A handbook. Renewable Energies, Munich, Germany, pp. 104.

Entry JA, Runion GB, Prior SA, Mitchell RJ, Rogers $\mathrm{HH}$ (1998). Influence of $\mathrm{CO}_{2}$ enrichment and nitrogen fertilization on tissue chemistry and carbon allocation in longleaf pine seedlings. Plant and Soil 200: 3-11. - doi: 10.1023/A: 1004305320030

Eppendorfer WH, Eggum BO (1994). Effects of sulphur, nitrogen, phosphorus, potassium, and water stress on dietary fibre fractions, starch, amino acids and on the biological value of potato protein. Plant Foods for Human Nutrition 45: 299-313. - doi: 10.1007/BF01088079

Field C, Mooney HA (1986). The photosynthesisnitrogen relationship in wild plants. In: "On the Economy of Plant Form and Function" (Givnish TJ eds). Cambridge University Press, Cambridge, UK, pp. 25-55.

Fredeen AL, Rao IM, Terry N (1989). Influence of phosphorus nutrition on growth and carbon partitioning in Glycine max. Plant Physiology 89: 225-230. - doi: 10.1104/pp.89.1.225

Frei M (2013). Lignin: characterization of a multifaceted crop component. The Scientific World Journal 13: 1-25. - doi: 10.1155/2013/436517

Gangawar MS, Parameshwaran PM (1976). Phosphorus and sulphur relationship in sunflower. II. Studies on P and sulfur nutrition. Oilseed Journal 6: 28-32.

Geiger H, Fuggerera H (1979). Über den chemismus der Wiesner-reaktion auf lignin [On the chemistry of the Wiesner reaction on lignin]. The Zeitschrift für Naturforschung B 34: 14711472. [in German] - doi: 10.1515/znb-1979-1028 Holford ICR (1997). Soil phosphorus: its measurement, and its uptake by plants. Soil Research 35 (2): 227. - doi: 10.1071/S96047

Hu F, Ragauskas A (2016). Pretreatment and lignocellulosic chemistry. Bioenergy Research 5: 1043-1066. - doi: 10.1007/s12155-012-9208-0

Huang JH, Xu J, Ye X, Luo TY, Ren LH, Fan GC, Qi YP, Li Q, Ferrarezi RS, Chen LS (2019). Magnesium deficiency affects secondary lignification of the vascular system in Citrus sinensis seedlings. Trees 33: 171-182. - doi: 10.1007/soo468018-1766-0

IPCC (2008). Synthesis of country progress reports. FAO, Rome, Italy.

Jørgensen $\mathrm{H}$, Vibe-Pedersen J, Larsen J, Felby C (2007). Liquefaction of lignocellulose at highsolids concentrations. Biotechnology and Bio- 
engineering 96: 862-870. - doi: 10.1002/bit.21115 Jung JY, Choi MS, Kim JS, Jeong MJ, Kim YW, Woon BT, Yeo JK, Shin HN, Goo YB, Rye KO, Karigar CS, Yang JK (2010). Enzymatic hydrolysate from non-pretreated biomass of yellow poplar (Liriodendron tulipifera) is an alternative resource for bioethanol production. Journal of Korean Forest Society 99: 744-749. [online] URL: http://www.researchgate.net/publication/ 263400238

Kadam KL, Chin CY, Brown LW (2008). Flexible biorefinery for producing fermentation sugars, lignin and pulp from corn stover. The Journal of Industrial Microbiology and Biotechnology 35 331-341. - doi: 10.1007/s10295-008-0322-0

Kader MA, Lindberg S (2010). Cytosolic calcium and $\mathrm{pH}$ signaling in plants under salinity stress. Plant Signaling and Behavior 5: 233-238. - doi: 10.4161/psb.5.3.10740

Kim HJ, Cho EJ, Lee KH, Kim SB (2011). Popping preatment for enzymatic hydrolysis of waste wood. Journal of the Korean Wood Science and Technology 39: 95-103. - doi: 10.5658/WOOD.20 11.39.1.95

Kramer PJ (1969). Plant and soil water relationships: a modern synthesis. McGraw Hill, New York, USA, pp. 59. [online] URL: http://www cabdirect.org/cabdirect/abstract/19690600125 Krishna SH, Chowdary GV (2000). Optimization of simultaneous saccharification and fermentation for the production of ethanol from biomass. Journal of Agricultural and Food Chem istry 48: 1971-1976. - doi: 10.1021/jf991296z Lambardi M, Fabbri A, Caccavale A (2000). Cryopreservation of white poplar (Populus alba L.) by vitrification of in vitro-grown shoot tips. Plant Cell Reports 19: 213-218. - doi: 10.1007/so 02990050001

Mandre M (2002). Relationships between lignin and nutrients in Picea abies L. under alkaline air pollution. Water, Air, and Soil Pollution 133 363-379. - doi: 10.1023/A:1012987503033 Miidla H (1989). Biochemistry of lignin forma tion. In: Publications in Plant Physiology and Plant Biochemistry 5 "The Formation of Lignin in Wheat Plants and its Connection with Min eral Nutrition". Acta et Commentationes Universitatis Tartuensis, Tartu, Finland, pp. 11-23. Murashige T, Skoog F (1962). A revised medium for rapid growth and bioassays with tobacco tissue culture. Physiologia Plantarum 15: 473 497. - doi: 10.1111/j.1399-3054.1962.tbo8052.x NREL (1996). LAP-002. In: "Chemical Analysis and Testing Laboratory Analytical Procedures". NREL, Golden, CO, USA, pp. 1-11.
Parvin K, Ahamed KU, Islam MM, Haque MN (2015). Response of tomato plant under salt stress: role of exogenous calcium. Journal of Plant Sciences 10 (6): 222-233. - doi: 10.3923/jps. 2015.222.233

Pearcy RW, Sims DA (1994). Photosynthetic acclimation to changing light environments: scaling from the leaf to the whole plant. In: "Exploitation of Environmental Heterogeneity by Plants" (Caldwell MM, Pearcy RW eds). Academic Press, Cambridge, MS, USA, pp. 145-174. [online] URL: http://books.google.com/books? id=59Tp1ulggfoC

Perry TO (1982). The ecology of tree roots and the practical significance thereof. Journal of Arboriculture 8: 197-211.

Rowe RL, Street RN, Taylor G (2009). Identifying potential environmental impacts of large-scale deployment of dedicated bioenergy crops in the UK. Renewable and Sustainable Energy Reviews 13: 271-290. - doi: 10.1016/j.rser.2007.07.0 08

Sannigrahi PJ, Ragauskas A, Tuskan GA (2010). Poplar as a feedstock for biofuels: a review of compositional characteristics. Biofuels, Bioproducts and Biorefining 4: 209-226. - doi: 10.1002/ bbb.206

Sewalt VJH, Glasser WG, Beauchemin KA (1997). Lignin impact on fiber degradation. 3. Reversal of inhibition of enzymatic hydrolysis by chemical modification of lignin and by additives. Journal of Agricultural and Food Chemistry 45: 18231828. - doi: $10.1021 /$ jf9608074

Shane MW, Lambers H (2005). Cluster roots: a curiosity in context. Plant and Soil 274: 101-125. doi: 10.1007/s11104-004-2725-7

Shibli R, Mohammad M, Abu-Ein A, Shatnawi M (2000). Growth and micronutrient acquisition of some apple varieties in response to gradual in vitro induced salinity. Journal of Plant Nutrition 23: 1209-1215. - doi: 10.1080/0190416000938 2094

Singh D, Chen S (2008). The white-rot fungus Phanerochaete chrysosporium: conditions for the production of lignin-degrading enzymes. Applied Microbiology and Biotechnology 81: 399-417. - doi: 10.1007/s00253-008-1706-9

Snyder V, Schmidt RE (1974). Nitrogen and iron fertilization on bentgrass. In: Proceedings of the " $2^{\text {nd }}$ International Turfgrass Research Conference" (Roberts EC ed). American Society of Agronomy and the Crop Science Society of America, Madison, WI, USA, pp. 176-185. - doi: 10.2135/1974. proc2ndintlturfgrass.c24

Sluiter A, Hames B, Ruiz R, Scarlata C, Sluiter J,
Templeton D, Crocker DLAP (2008). Determination of structural carbohydrates and lignin in biomass. Laboratory Analytical Procedure (LAP). Technical Report NREL/TP-510-42618, National Renewable Energy Laboratory, Boulder, CO, USA, pp. 1-16.

Spangler DJ, Emert GH (1986). Simultaneous saccharification and fermentation with Zymomonas mobilis. Biotechnology and Bioengineering 28: 115-118. - doi: 10.1002/bit.260280118 Talukdar D (2012). Exogenous calcium alleviates the impact of cadmium-induced oxidative stress in Lens culinaris Medic. seedlings through modulation of antioxidant enzyme activities. Journal of Crop Science and Biotechnology 15: 325-334. - doi: 10.1007/s12892-012-0065-3

Tillman DA (2000). Biomass cofiring: the technology, the experience, the combustion consequences. Biomass and Bioenergy 19: 365-384. doi: 10.1016/Sog61-9534(00)00049-0

Tullus A, Mandre M, Soo T, Tullus H (2010). Relationships between cellulose, lignin and nutrients in the stemwood of hybrid aspen in Estonian plantations. Cellulose Chemistry and Technology 44: 101-109. [online] URL: http://www. cellulosechemtechnol.ro/pdf/CCT44.4-6(2010)/1 01-109.pdf

Waring RH (1991). Responses of evergreen trees to multiple stresses. In: "Response of Plants to Multiple Stresses” (Mooney HA, Winner WE, Pell EJ eds). Academic Press, San Diego, CA, USA, pp. 371-390. - doi: 10.1016/B978-0-08-0924 83-0.50022-0

Wise LE, Urphy MM, D’Addieco AA (1946). Chlorite holocellulose, its fractionation and bearing on summative wood analysis and studies on the hemicelluloses. Paper Trade Journal 122: 3543.

Yan L, Xu X (2018). Higher response of terrestrial plant growth to ammonium than nitrate addition. Biogeosciences Discussions 124: 1-28. [online] URL: http://d-nb.info/1161054200/34 Youe WJ, Kim YS, Kang KY (2015). Evaluation of pitch pine for bioethanol production by organosolv pretreatment. Journal of Korea Technical Association Pulp and Paper Industry 47: 2129. - doi: 10.7584/ktappi.2015.47.4.021

Zhang W, Wu L, Ding Y, Yao X, Wu X, Weng F, Li G, Liu Z, Tang S, Ding C, Wang S (2017). Nitrogen fertilizer application affects lodging resistance by altering secondary cell wall synthesis in japonica rice (Oryza sativa). Journal Plant Research 130: 859-871. - doi: 10.1007/s10265-017$0943-3$ 